\title{
EVALUATION OF THE LOGISTICS CENTER LOCATIONS USING A MULTI-CRITERIA SPATIAL APPROACH
}

\author{
İsmail Önden ${ }^{1}$, Avni Zafer Acar ${ }^{2}$, Fahrettin Eldemir ${ }^{3}$ \\ ${ }^{1}$ Turkish Institute of Management Sciences, Transportation and Logistics Research Group, Turkey \\ ${ }^{2}$ Dept of International Logistics and Transportation, Piri Reis University, Turkey \\ ${ }^{3}$ Dept of Industrial Engineering, Yildiz Technical University, Turkey
}

Submitted 29 September 2014; resubmitted 20 February 2015, 25 June 2015; accepted 2 October 2015; published online 25 May 2016

\begin{abstract}
The private sector assumes that logistics centers create cost benefits for their operations. On the other hand, the public sector also assumes that logistics sectors maintain harmony with an aim to improve the logistics network structure and efficiency. In Turkey, nineteen logistics centers are on-going to develop a system approach and integrate different transportation modes to increase logistics performance. In this study, we focused on a multi-stage methodology that combines the fuzzy analytic hierarchy process, spatial statistics and analysis approaches to evaluate the suitability degrees of the logistics centers in the study area. To reach the suitability levels, seven decision criteria were considered alongside their priority levels. These criteria were proximities to highway, railway, airports, and seaports; volume of international trade; total population; and handling capabilities of the ports. The reached suitability degrees were tested using a sensitivity analysis. Different scenarios were discussed to understand how the decision environment might illustrate differences in spatial aspect.
\end{abstract}

Keywords: suitability analysis; logistics center; sustainable logistics management; geographic information systems (GIS); fuzzy analytic hierarchy process (F-AHP).

\section{Introduction}

It is commonly accepted that heightened global competition characterizes today's marketplace. The concept of competition in business environment can be seen as a continuous race rather than a target. The competitive advantage of an institution regarding its power position in the market is not permanent, and it can change in time. Today's competition among firms, industries, and even countries is accepted as an inescapable phenomenon. Thus, in such situations, countries need to evaluate their competitive positions using valid indexes, such as the human development index, logistics performance index, global competitiveness index, and doing business index. For economies that are not satisfied with their positions, such as Turkey, this is an unofficial obligation. Turkey has targeted higher positions in these indexes by developing its infrastructure and enforcing high-level foreign trade objectives.

Due to the mentioned expectations and economic dynamism, the country needs to develop the entire infrastructure to achieve its goal. Additionally, it is well known that globalization requires economies to have competitive logistics systems to provide sustainable development. Therefore, the government has started to play a role of strategic leader and planner in logistics for both the producers and logistics firms to foster economic growth. This is not surprising, because under the continuous pressure of global competition, in many cases, logistics seems to be a potential topic of improvement because it covers a significant portion of the overall supply chain costs of the firms and the economies.

Logistics have been defined as 'the process of strategically managing the procurement, movement and storage of materials, parts and finished inventory through the firm and its marketing channels in such a way that current and future profitability are maximized through the cost effective fulfilment of orders' (Christopher 2016). Today, logistics and its costs are identified as one of the major drivers affecting the competitiveness of countries (Guasch, Kogan 2001). Moreover, logistics plays a vital role in maintaining economic prosperity, social well-being, and everyday life (McKinnon 2009; Rantasila, Ojala 2012).

Corresponding author: İsmail Önden

E-mails: ismail.onden@tubitak.gov.tr; ismailonden@gmail.com 
According to Rodrigues et al. (2005), global logistics costs were estimated at USD 6732 billion in the year 2002, which corresponded to $13.8 \%$ of the world's GDP in the same year (Rodrigues et al. 2005). Logistics costs were $14.7 \%$ of South Africa's GDP in $2004,9.4 \%$ of USA's GDP in 2009 (Wittmann 2010), and 8-12\% of the GDP in Turkey (Deloitte 2013). Roughly more than 400 thousand people were employed in logistics and logistics related roles in 2011 (UTIKAD 2012).

At the strategic level, one of the most important decisions in logistics concerns the costs of the location selection. However, overall logistics costs will not be reduced if every firm selects a convenient place to locate themselves separately. In this case, firms need to have logistics centers to consolidate all freight, warehousing, and material handling activities with an aim to reduce the logistics costs in integrated manner.

Logistics centers are specific centers where various logistic based activities are performed. These activities can include distribution, storage, transportation, consolidation, handling, customs clearance, imports, exports, transit processes, infrastructural services, insurance, and banking. These centers are defined for all national and international logistic and related operations (Erkayman et al. 2011).

Logistics centers are growing in importance both in the upstream and downstream stages of the supply chain processes of many industries. Particularly, manufacturers focus more on reducing costs while logistics centers provide cost benefits of consolidation. Moreover, they seek to increase customer satisfaction and optimize their supply chain to resources, suppliers, and customers; hence, they are paying much more attention to the number and location of their distribution facilities, and consequently, to the functions they perform (Rodrigue et al. 2013; Cuomo 2008). Logistics centers also contribute to the performance of logistics services by integrating various transportation modes and consolidating goods and activities.

Transportation is a well-known facet of logistics. Accordingly, the name of freight village that facilitates intermodal transportation is often used instead of logistics center. A logistics center is primarily an inter-modal terminal, which is the principal component of the intermodal transport chain that constitutes the node where the transhipment of goods from one mode to the other takes place. Logistics centers must be settled near production and commercial centers, highways, railways, airports and, if possible, seaports (Erkayman et al. 2011). However, a logistics center is more than a freight village or intermodal terminal, as it provides many other logistics-related services mentioned before.

To this end, it will be helpful to articulate intermodal transportation to prevent conflicts. There is a consensus in definitions that inter-modal transport constitutes a transportation process in which at least two of the following conditions are fulfilled. First, two or more different transport modes (e.g., truck, train, ship, plane) are deployed. The second is that the goods remain in one and hence the same transport load unit for the entire journey (Tsamboulas, Kapros 2003) from shipping point to the delivery point.

The location of the logistics centers is a key element in enhancing the efficiency of freight transport systems and initializing relative supply chain activities sufficiently. Thus, the location of a logistics center should be selected strategically. Otherwise, it may have irreversible consequences on the overall logistics costs and may create bottlenecks that lead to rapid increases in costs through providing the transportation solutions. All factors that influence the determination of a location should be considered and well planned. Hence, public authorities should consider the importance of this topic in terms of strong economic, social, and environmental implications before announcing an area as a logistics center (Kayikci 2010).

Considering Turkish Republic's history, logistics has appeared for the first time in the new ' 5 year Development Plan' prepared by the Ministry of Development to reach the macroeconomic aims during the period from 2014 to 2018 . This is a strategic leverage, and it can be interpreted as a breaking point. The government released a strategic plan entitled 'strengthening combined transport in Turkey' and a strategic shifting program from transportation to logistics. According to this plan and programs in 19 locations, TCDD (Turkish State Railways) started to plan and build logistic centers close to relevant cities.

The aim of this study is to propose a methodology that integrates a multi-criteria approach with Geographic Information System (GIS) to evaluate logistics center locations. The results of the study provide spatial suitability of these announced logistics centers. The suitability refers to a most suitable area located closest to the accessible, highly populated, and trade zones based on the spatial analysis. To calculate the suitability values, the study area was divided into sub-parts and the values of the logistics centers were compared with the calculated values. To get these calculation values, experts were asked to select seven decision criteria. Various GIS analyses were proposed to integrate with the F-AHP technique.

To this end, the rest of this paper is structured as follows. The following chapter discusses the characteristics of the focused study area and decision criteria. The methodology is explained and the theoretical backgrounds of the used techniques are given. Following the description of the methodology, the evaluation process and mapping of the suitability analysis is detailed. The final chapter is devoted to summarizing the results of the study. Concluding discussions are also presented.

\section{Decision Environment}

Turkey was selected as the study area due to logistics centers being in the construction and planning process to gear up competitiveness in logistics. The logistics activities are an example of a decentralized system; each company has to design their own logistics structure. In this case, some disadvantages have been discussed in previous studies based on the square root law (Maister 1976). On the other hand, it is accepted that a logistics 
center has a positive influence on the growth of the local economy in the establishing region. Accordingly, local authorities want their region to be considered, when deciding about the new logistics centers. However, rising logistics costs, increasing travel distances by trucks, and lacking multi-modal transportation ability may be experienced in locating a logistics center in unsuitable locations. To overcome these problems and provide benefits to the entire system, objective decisions for the centers should be provided. Thus, the influential criteria should be considered. The experts of the location selection processes and the logistics management should consider proper decision criteria.

The problem of logistics center location is an example of a multi-dimensional problem. These dimensions include accessibility (Dablanc 2007; Kayikci 2010; Sengpiehl et al. 2009), quality of transportation and infrastructure (Vlachopoulou et al. 2001), and multi-modal transportation availability, which all influence the decision. Non-spatial factors also need to be considered, such as demographics, labour availability (Eryürük et al. 2012; Tsamboulas, Kapros 2003), and the volume of international trade in determining convenient areas for the new facilities.

In this study, four experts were selected as Decision-Makers (DMs) due to their experiments with the decision environment. One expert is a senior-executive in the finance sector who focuses on international trade activities and export, one expert is a logistics operation manager in a multi-national company, one expert is a professor of location science and supply chain management and represents the academic opinion, and one expert is the advisor of the metropolitan logistics and transportation planning department of the regional government. These people are believed to be competent in expressing the criteria that have an influence on our problem.

DMs have accepted seven criteria that are significant for the study based on group decision-making approach. The criteria are illustrated in Fig. 1 utilizing a single hierarchy based on the experiences of the DMs. Despite no hierarchy among the decision criteria, the accepted factors can be separated in two clusters: a distance based criteria cluster and a non-geographic criteria cluster.

The first factors are based on proximities to major transportation modes, such as seaports (Dablanc 2007; Nathanail 2007; Sengpiehl et al. 2009), airport nodes, railways (Dablanc 2007; Nathanail 2007) and motorway (highway) networks (Dablanc 2007; Eryürük et al. 2012; Nathanail 2007; Sengpiehl et al. 2009; Uçal Sarı et al. 2013). These criteria represent the capability of the movement of the goods by the existing transportation infrastructure. On the other hand, the total population criteria are accepted as decision criteria representing the labour availability of the region (Ashrafzadeh et al. 2012; Durmuş, Turk 2014; Eryürük et al. 2012). The volume of international trade suggests which city is best for creating supply and demand; thus, this data is needed to distribute information about transportation companies. Proximity to supply (Ashrafzadeh et al. 2012; Dablanc 2007; Demirel et al. 2010; Durmuş, Turk 2014; Eryürük et al. 2012; Özcan et al. 2011; Özdemir 2010; Uçal Sarı et al. 2013) are also crucial for determining the location of the new logistics center, due to their volume of freight between the regional and global markets. Owing to the location of the seaports, we cannot represent the size of the facilities; however, we can consider the flow densities of the seaports to better understand, which areas have required infrastructure for maritime transportation.

\section{Methodology}

The current study evaluated the locations of an on-going logistics center project of the TCDD via a multi-disciplinary approach using multi-step methodology. Two main approaches can be used to reach the suitability levels of the alternatives. The first is the F-AHP, which is the most frequently used multi-criteria decision-making and evaluation tool to better understand how the decision criteria influence decision environment. The aim of using F-AHP technique is to prioritize the decision criteria. The second approach is spatial analysis and spatial statistics to better understand the proximities to the alternative nodes, the ways in which the decision criteria are sprawled on the study area, as well as the ways in which these scatterings on the plane affect the suitability levels of the candidates. For these reasons, F-AHP and GIS/Spatial analyses have been suggested and utilized in this study.

According to the proposed methodology, illustrated in Fig. 2, the solution approach starts with the determination of the decision criteria. After accepting the particular decision criteria as significant for the study structure, these items need to be converted to the geographic data for the analysis, even though they are non-spatial data. In the second step, the methodology uses GIS analytic approach capabilities with three different analyses to reach maps, which represent the criteria effects on the study area. After calculating the criteria maps, these maps are needed to be overlaid; in these steps, the weights of the criteria will be determined.

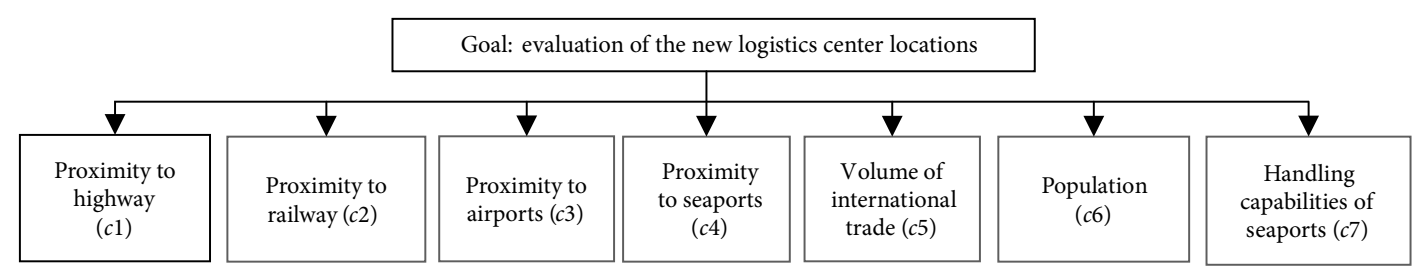

Fig.1. Decision criteria 


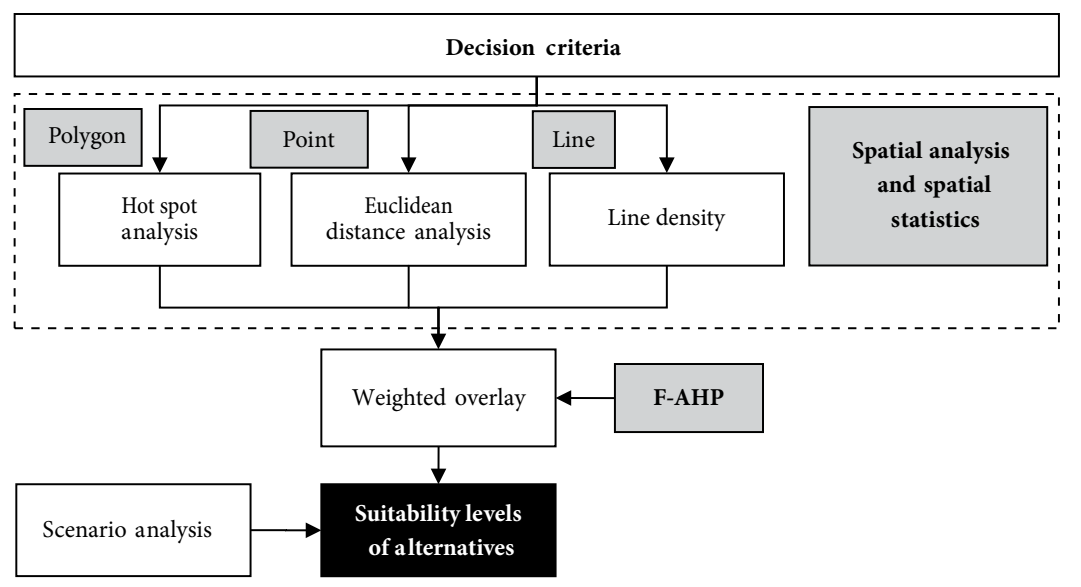

Fig. 2. Methodology

The priority weights are calculated with F-AHP. The experts' thoughts are represented with a linguistic scale and pairwise comparisons that constitute the comparisons of the F-AHP method. The results of the overlaying step will be the suitability map, which will be the convenience levels of the alternatives. On the other hand, the final suitability map may not represent the possible changes. Thus, a scenario analysis is also proposed to better understand the sensitivity of the decision environment.

The following sections review the theoretical background of the analysis methods as well as the application of the proposed techniques to the actual evaluations.

\subsection{Spatial Analysis}

GIS is a well-known analysis tool for location analysis, as it is able to find solutions to both discrete and continuous location problems (Liu et al. 2006; Ocalir et al. 2010; Zhou, Wu 2012). It can also be used to calculate hot spots. It measures the distances that reach the density levels of the different data types, such as point, line, and polygons. GIS is also used to calculate the suitability levels of the alternatives with an integration of the multi-criteria approaches (Jankowski, Richard 1994; Zucca et al. 2008).

Within the study, we aimed to integrate GIS's analytical abilities to measure the decision criteria's effects on the study area. However, the data types for the decision criteria may illustrate the variety that makes use of the different analysis approaches as a necessity to reach the suitability maps. Thus, the hot spot analysis is proposed to measure the statistical hotspots of the considered regions for a set of sub-regions for the economic and demographic data.

On the other hand, line density measures line data and a Euclidean distance analysis measures the effects of the point data. After building a GEOgraphic DataBase (GeoDb) and measuring the necessary distance-based maps, the maps needed to be reclassified to better represent the calculations into the same scale. During the reclassification process, Jenks' natural breaks classification method (Jenks 1967) was applied. After the reclassification of the calculated map, the overlay tool can be used to integrate and create the suitability map with regard to the priority weights of the factors that influence the decision environment (Onden et al. 2012).

\subsubsection{Line Density Analysis}

Line density focuses on the neighborhood density of the output raster cells of the linear features (Fig. 3). To reach the densities, Eq. (1) is used, where $L 1, L 2$ represents the length of the portion of each line that falls within the circle. The circle is drawn around each raster cell using the search radius and the length of the portion of each line is multiplied by its population field value (ArcGIS Resources 2016). The $V 1$ and $V 2$ values represent the population values of the grids. The line density value can be calculated as:

$$
\text { Line density }=\frac{(L 1 \cdot V 1)+(L 2 \cdot V 2)}{\text { Area of circle }} .
$$

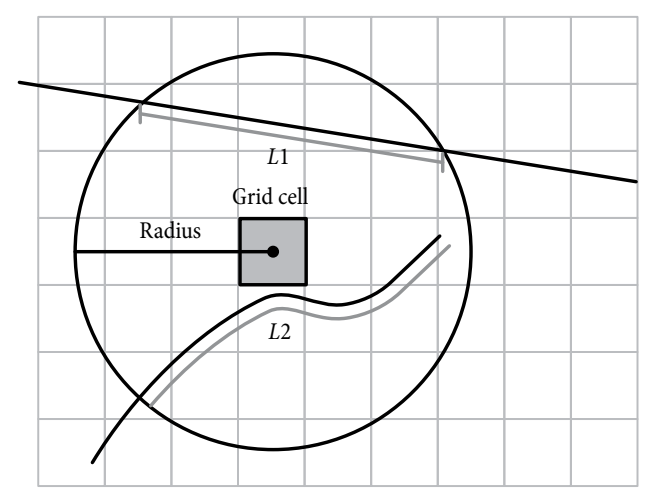

Fig. 3. Circular neighborhood for the determination of the line length density (McCoy et al. 2004)

\subsubsection{Hot Spot Analysis}

A hot spot analysis is a spatial statistics tool for measuring the spatial specialties of the geographic database based on the Moran's I statistics. The analysis tool has been applied to different study areas, such as crime mapping (Levine 2006) and traffic accident mappings (Erdogan et al. 2008; Truong, Somenahalli 2011). Moran's I 
index measures the spatial autocorrelation of the study area's spatial pattern based on the similarities of the attributes and an index consisting of the location proximities. The calculation of the index $I$ can be seen as follows, where $w_{i j}$ is the proximity weight of location $i$ and location $j$ (where $w_{i i}=0 ; x_{i}$ is the severity index at location $j ; x$ is the global mean value; $n$ is the total number of focused location):

$$
I=\frac{n \sum_{i=1}^{n} \sum_{j=1}^{n} w_{i j}\left(x_{i}-\bar{x}\right) \cdot\left(x_{j}-\bar{x}\right)}{\left(\sum_{i=1}^{n} \sum_{j=1}^{n} w_{i j}\right) \cdot\left(\sum_{i}^{n}\left(x_{i}-\bar{x}\right)^{2}\right)} .
$$

Z-score methods can determine the statistical significance of Moran's I. Eq. (2) shows the mathematical formulation using the expected values $E(I)$ for a random pattern and the variances $\operatorname{VAR}(I)$ :

$$
Z=\frac{I-E(I)}{\sqrt{\operatorname{VAR}(I)}} .
$$

A convenient distance threshold value should be found where the spatial autocorrelation is maximized, since each data point is analysed in terms of its neighbouring data points defined by a distance threshold. The maximum value of the $z$ value can be reached by empirical testing. Thus, to obtain the highest $z$ values, different distance threshold values should be considered. According to the obtained $z$ values, the best value is accepted as the convenient threshold distance. The $z$ value illustrates whether the data is clustered or randomly distributed with a determined significance level.

The Getis-Ord statistics are used to specify the hot spot (Getis, Ord 1992). The high value of the Getis-Ord statistics indicates that the region has a high value (hot spot) of the considered activity in the area. Mathematically, the representation of the Getis-Ord $G_{i}^{*}$ statistics can be seen as follows:

$$
\begin{aligned}
G_{i}^{*}(d) & =\frac{\sum_{j=1}^{n} w_{i j}(d) x_{j}}{\sum_{j=1}^{n} x_{j}} ; \\
Z\left(G_{i}^{*}\right) & =\frac{I-E(I)}{\sqrt{\operatorname{VAR}(I)}} .
\end{aligned}
$$

\subsubsection{Euclidean Distance Analysis}

The Euclidean distance analysis calculates the distances between the point data according to their location on the plane. The distances are calculated from the center of the source cell to the center of the surrounding cells, which is illustrated in Fig. 3. The Euclidean distance algorithm calculates the distances from each source cell to other cells by calculating the hypotenuse with a maximum value of $x$ and a maximum value of $y$ as the other two legs of the triangle. With this calculation approach, the true Euclidean distances can be derived instead of the cell distances. The shortest distance to a source is then determined. If it is less than the specified maximum distance, the value is assigned to the cell location on the output raster (McCoy et al. 2004).

\subsection{F-AHP}

The AHP technique was originally proposed by Saaty (2008, 1990). After the appearance of the technique, due to its practicability and simplicity, the AHP became one of the most frequently used multi-criteria decisionmaking techniques in the literature. Due to its analytical abilities, it has been integrated with the fuzzy logic approach to make better decisions.

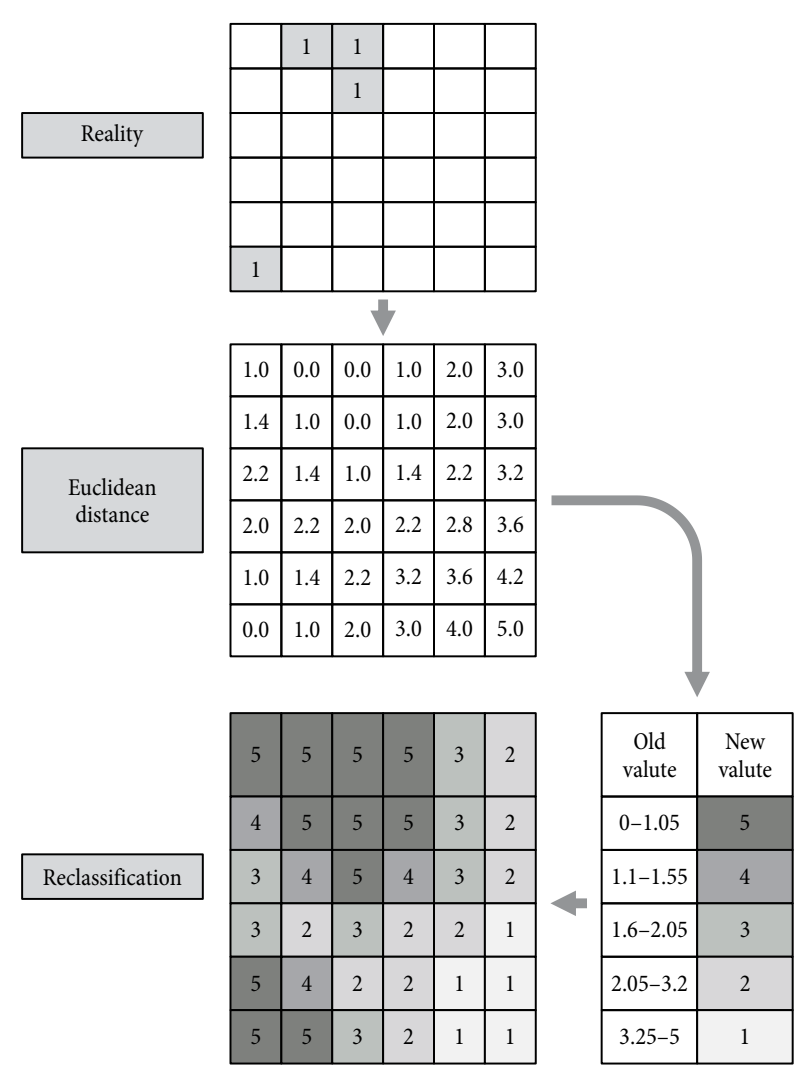

Fig. 4. How the Euclidean analysis and reclassification works (Gumus, Onden 2014)

The F-AHP utilizes various calculations to reach decisions. The fuzzy approach for the technique was proposed to compare the fuzzy ratios described with triangular values (Van Laarhoven, Pedrycz 1983). After the first approach, Buckley (1985) proposed a new approach to the AHP. Chang (1996) also proposed different fuzzy approaches, such as the fuzzy extent analysis, to calculate the preferences.

Due to the popularity of the technique, it has been applied in many research areas (Kahraman et al. 2014, 2009; Mon et al. 1994), including location selection problems. Different location problems are considered via the AHP and F-AHP approaches (Al-Harbi 2001; Kuo et al. 2002; Vahidnia et al. 2009), as these techniques can achieve a convenient location decision. Because the technique is accepted as a suitable tool for making evaluations and reaching decisions, it has been accepted as a part of the proposed methodology for determining the priorities of the decision criteria. 
In the study, Buckley's fuzzy AHP approach (Buckley 1985) is preferred with linguistic scale and triangular fuzzy numbers. Within these calculations Bozdağ et al. (2003) triangular scale was used for the pair-wise comparisons due to its convenience and the linguistic comparison expressions, the representations of which are expressed in Table 1. The Buckley's method was used because of its ability of priority calculation of the considered criteria. On the other hand, extent analysis has been criticized (Wang et al. 2008), and it is known that the Van Laarhoven and Pedrycz's (1983) F-AHP leads to unnecessary calculations, which sometimes lead to impossible solutions.

The F-AHP approach can be explained in three steps. In the following paragraphs, we briefly explain how the F-AHP technique is used in the study, as well as what references are used to reach the priority levels of the decision criteria.

In the 1st step of the F-AHP, comparison matrices of the decision criteria is constructed. $\tilde{c}_{i j}$ is the linguistic comparison value of each criterion in the comparison matrix $C$. The structure of the comparison matrix $\tilde{C}_{k}$, which represents each expert $k$ 's judgments, can be seen as follows:

$$
\begin{aligned}
& \tilde{C}_{k}=\left[\begin{array}{cccc}
1 & \tilde{a}_{12} & \cdots & \tilde{a}_{1 n} \\
\tilde{a}_{21} & 1 & \cdots & \tilde{a}_{2 n} \\
\vdots & \vdots & \ddots & \vdots \\
\tilde{a}_{n 1} & \tilde{a}_{n 2} & \cdots & 1
\end{array}\right]= \\
& {\left[\begin{array}{cccc}
1 & \tilde{a}_{12} & \cdots & \tilde{a}_{1 n} \\
1 / \tilde{a}_{12} & 1 & \cdots & \tilde{a}_{2 n} \\
\vdots & \vdots & \ddots & \vdots \\
1 / \tilde{a}_{1 n} & 1 / \tilde{a}_{2 n} & \cdots & 1
\end{array}\right], k=1,2, \ldots, n .}
\end{aligned}
$$

In the 2nd step, weights are determined using the Buckley's (1985) approach (where $\tilde{r}_{i}$ is the geometric means of the fuzzy values and $\tilde{w}_{i}\left(L_{i}, M_{i}, U_{i}\right)$ is the fuzzy weight of the $i$-th criterion with lower, median, and upper triangular values) as:

$$
\begin{aligned}
& \tilde{r}_{i}=\left(\tilde{a}_{i 1} \otimes \tilde{a}_{i 1} \otimes \ldots \otimes \tilde{a}_{i n}\right)^{\frac{1}{n}} ; \\
& \tilde{w}_{i}=\tilde{r}_{i} \otimes\left(\tilde{a}_{i 1} \oplus \tilde{a}_{i 1} \oplus \ldots \oplus \tilde{a}_{i n}\right)^{-1} .
\end{aligned}
$$

In 3rd step, the defuzzification of the triangular fuzzy numbers into a crisp values can be done after the calculation of the fuzzy relative matrix is obtained. During this process, the total integration value method with an index optimism $\omega \in[0,1]$ is used (Liou, Wang 1992). In that calculation, a fuzzy number $A$ is a subset of real line $R$ of which the membership function $f_{A}(x)$ can be continuously mapped from $R$ into a closed interval $[0, w]$ where $0 \leq w \leq 1$ (Purba et al. 2010).

Let $\tilde{A}$ be a fuzzy number with a left membership function $f_{\tilde{A}}^{L}$ and a right membership function $f_{\tilde{A}}^{R}$. As such, the total integration value is defined as (Kahraman et al. 2014, 2004):

$$
E_{\omega}=\omega E_{R}(\tilde{A})+(1-\omega) E_{L}(\tilde{A})
$$

here:

$$
E_{R}=\int_{\propto}^{\beta} x f_{\tilde{A}}^{R}(x) d x
$$

and

$$
E_{L}=\int_{\gamma}^{\delta} x f_{\tilde{A}}^{L}(x) d x,
$$

where: $-\infty \gamma \alpha \leq \beta \leq \gamma \leq \delta<\infty$.

The total integral value can be obtained for a triangular fuzzy number $\tilde{A}=(a, b, c)$ as:

$$
E_{\omega}=\frac{1}{2}(\omega(a+b)+(1-\omega)(b+c)) \text {. }
$$

\section{Evaluation Process and Application}

The previous chapters introduced the theoretical background of the proposed methodology and offered a brief explanation of the recommended analytical methods. This chapter is devoted to explain how the suitability analysis can be performed based on the discussed methodology and how sustainable logistics center locations can be determined with the multiple criteria approach. As illustrated in Fig. 2, the methodology starts with a decision criteria determination. During this process, previous studies and experts' thoughts are considered. Seven decision criteria that have an influence on the study area are proposed.

After determining the problem, the ESRI ArcGIS 10 package program (http://www.esri.com/software/arcgis/arcgis-for-desktop) was selected to perform the spatial statistics analyses. For the calculations, the geographic data were needed and different official databases were used as data sources. The railway networks $c 1$, road networks $c 2$, and airport locations $c 3$ data were gathered from ESRI's database. The international trade $c 5$ and total population $c 6$ data were collected from the Turkish Statistical Institute (TUIK 2014a, 2014b). Seaport locations $c 4$ and the volume of the handling in the

Table 1. The fuzzy importance degrees (Bozdağ et al. 2003)

\begin{tabular}{|l|c|c|c|c|}
\hline Linguistic importance & Fuzzy scale & Abbreviation & Reciprocal fuzzy scale & Abbreviation \\
\hline Equally important & $(1,1,1)$ & $E q$ & $(1,1,1)$ & $1 / E q$ \\
\hline Weakly important & $(5 / 2,3,7 / 2)$ & $W k$ & $(2 / 7,1 / 3,2 / 5)$ & $1 / W k$ \\
\hline Essentially important & $(9 / 2,5,11 / 2)$ & $E s$ & $(2 / 11,1 / 5,2 / 9)$ & $1 / E s$ \\
\hline Very strongly important & $(13 / 2,7,15 / 2)$ & $V s$ & $(2 / 15,1 / 7,1 / 13)$ & $1 / V s$ \\
\hline Absolutely important & $(17 / 2,9,19 / 2)$ & $A b$ & $(2 / 19,1 / 9,2 / 17)$ & $1 / A b$ \\
\hline
\end{tabular}


ports $c 7$ data were gathered from the Turkish Ministry of Transport, Maritime and Communications database (RTMTMC 2014). After completing the data collection process, all data was manipulated to be ready for the analysis, as illustrated in Fig. 5.

\subsection{Priority Calculation}

F-AHP is accepted as the tool for the determination of the criteria priorities. To reach the criteria priorities, linguistics evaluations were conducted by the DMs with interviews under study group's care. The linguistic evaluations of the DMs are expressed in Table 2. After completing all interviews, these linguistic evaluations were converted to fuzzy triangular numbers to express the thoughts of the DMs. The conversion was done with the expressed scale and calculations were completed with Buckley's F-AHP method (Buckley 1985). In the last step, the fuzzy weights $\tilde{w}_{i}$ were computed and the calculated triangular fuzzy values were defuzzified using Liou and Wang's total integration method (Liou, Wang 1992). The fuzzy values and defuzzified weight values are expressed in the Table 3. Following the pair-wise comparisons, the geometric means of the fuzzy triangular numbers were calculated, and the results are given in Table 4 . These values are used to finalize the calculation of the priorities of the decision criteria. The calculated $w_{i}$ values express how the $i$-th criteria have an influence on

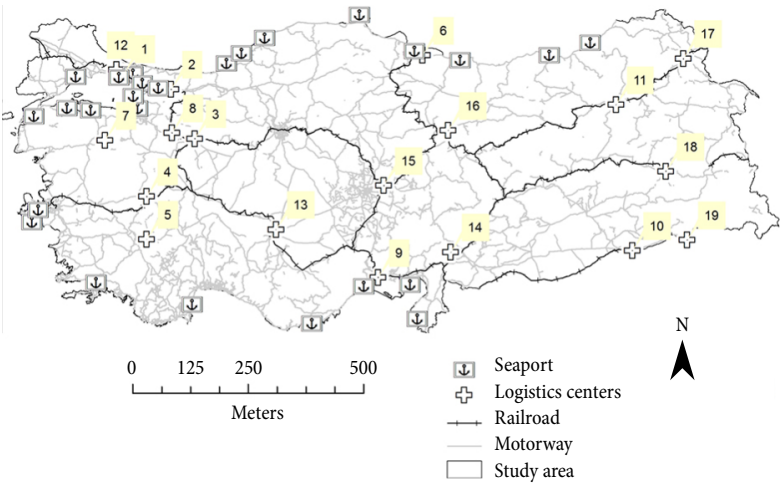

Fig. 5. Data, alternatives and study area

Table 4. Calculated priority values of the decision criteria

\begin{tabular}{|c|c|c|}
\cline { 2 - 3 } \multicolumn{1}{c|}{} & Fuzzy value & Defuzzied and normalized value \\
\hline$w 1$ & $(0.247,0.29,0.337)$ & 0.289 \\
\hline$w 2$ & $(0.207,0.246,0.289)$ & 0.245 \\
\hline$w 3$ & $(0.069,0.081,0.095)$ & 0.081 \\
\hline$w 4$ & $(0.072,0.085,0.099)$ & 0.084 \\
\hline$w 5$ & $(0.136,0.158,0.188)$ & 0.158 \\
\hline$w 6$ & $(0.034,0.04,0.047)$ & 0.040 \\
\hline$w 7$ & $(0.083,0.1,0.122)$ & 0.100 \\
\hline
\end{tabular}

Table 2. Decision-makers' evaluations for the criteria

\begin{tabular}{|c|c|c|c|c|c|c|c|c|c|c|c|c|c|c|}
\hline & \multicolumn{7}{|c|}{ DM1 } & \multicolumn{7}{|c|}{ DM2 } \\
\hline & $c 1$ & $c 2$ & $c 3$ & $c 4$ & $c 5$ & $c 6$ & $c 7$ & $c 1$ & $c 2$ & $c 3$ & $c 4$ & $c 5$ & $c 6$ & $c 7$ \\
\hline$c 1$ & - & $E q$ & $E s$ & $E s$ & $W k$ & Es & $W k$ & - & $W k$ & $E s$ & Es & $E q$ & $V s$ & Es \\
\hline$c 2$ & & - & $E s$ & $E s$ & $W k$ & Es & $W k$ & & - & $E s$ & $W k$ & $1 / W k$ & $E s$ & $W k$ \\
\hline$c 3$ & & & - & $E q$ & $1 / W k$ & $E q$ & $1 / W k$ & & & - & $E q$ & $1 / E s$ & $W k$ & $E q$ \\
\hline$c 4$ & & & & - & $1 / W k$ & $1 / W k$ & $1 / W k$ & & & & - & $1 / E s$ & $E q$ & $E q$ \\
\hline$c 5$ & & & & & - & $W k$ & $E q$ & & & & & - & $V s$ & Es \\
\hline$c 6$ & & & & & & - & $1 / W k$ & & & & & & - & $1 / W k$ \\
\hline \multirow[t]{3}{*}{$c 7$} & & & & & & & - & & & & & & & - \\
\hline & \multicolumn{7}{|c|}{ DM3 } & \multicolumn{7}{|c|}{ DM4 } \\
\hline & $c 1$ & $c 2$ & $c 3$ & $c 4$ & $c 5$ & $c 6$ & $c 7$ & $c 1$ & $c 2$ & $c 3$ & $c 4$ & $c 5$ & $c 6$ & $c 7$ \\
\hline$c 1$ & - & $E q$ & $E q$ & $E q$ & $E s$ & $V s$ & $W k$ & - & $E q$ & $E s$ & $W k$ & $E q$ & $V s$ & $W k$ \\
\hline$c 2$ & & - & $E q$ & $E q$ & $E s$ & $V s$ & $W k$ & & - & $E s$ & $W k$ & $E q$ & $V s$ & $W k$ \\
\hline$c 3$ & & & - & $E q$ & $E s$ & $V s$ & $W k$ & & & - & $1 / W k$ & $1 / E s$ & $W k$ & $1 / W k$ \\
\hline$c 4$ & & & & - & Es & $W k$ & $W k$ & & & & - & $1 / W k$ & $E q$ & $E q$ \\
\hline$c 5$ & & & & & - & $W k$ & $1 / \mathrm{Wk}$ & & & & & - & $V s$ & $W k$ \\
\hline$c 6$ & & & & & & - & $1 / E s$ & & & & & & - & $1 / E s$ \\
\hline$c 7$ & & & & & & & - & & & & & & & - \\
\hline
\end{tabular}

Table 3. Geometric means of the fuzzy evaluation matrix with respect to the goal

\begin{tabular}{|c|c|c|c|c|c|c|c|}
\cline { 2 - 7 } \multicolumn{1}{c|}{} & $c 1$ & $c 2$ & $c 3$ & $c 4$ & $c 5$ & $c 6$ \\
\hline$c 1$ & $(1,1,1)$ & $(1.257,1.316,1.368)$ & $(3.09,3.344,3.591)$ & $(2.667,2.943,3.208)$ & $(1.831,1.968,2.095)$ & $(5.929,6.435,6.94)$ & $(2.896,3.409,3.919)$ \\
\hline$c 2$ & $(0.731,0.76,0.795)$ & $(1,1,1)$ & $(3.09,3.344,3.591)$ & $(2.303,2.59,2.865)$ & $(1.339,1.495,1.666)$ & $(5.408,5.916,6.423)$ & $(2.5,3,3.5)$ \\
\hline$c 3$ & $(0.278,0.299,0.324)$ & $(0.278,0.299,0.324)$ & $(1,1,1)$ & $(0.731,0.76,0.795)$ & $(0.454,0.508,0.574)$ & $(2.525,2.817,3.096)$ & $(0.672,0.76,0.865)$ \\
\hline$c 4$ & $(0.312,0.34,0.375)$ & $(0.349,0.386,0.434)$ & $(1.257,1.316,1.368)$ & $(1,1,1)$ & $(0.508,0.577,0.665)$ & $(0.919,1,1.088)$ & $(0.919,1,1.088)$ \\
\hline$c 5$ & $(0.477,0.508,0.546)$ & $(0.6,0.669,0.747)$ & $(2.121,1.968,2.202)$ & $(1.504,1.732,1.967)$ & $(1,1,1)$ & $(4.031,4.583,5.123)$ & $(1.339,1.495,1.666)$ \\
\hline$c 6$ & $(0.144,0.155,0.169)$ & $(0.168,0.169,0.185)$ & $(0.323,0.355,0.396)$ & $(0.919,1,1.088)$ & $(0.195,0.218,0.248)$ & $(1,1,1)$ \\
\hline$c 7$ & $(0.255,0.293,0.345)$ & $(0.286,0.333,0.4)$ & $(1.156,1.316,1.488)$ & $(0.919,1,1.088)$ & $(0.6,0.669,0.747)$ & $(3.354,3.873,4.387)$ & $(1,1,1)$ \\
\hline
\end{tabular}


the decision environment. As expressed in the methodology, the reached priority values of the decision criteria will be used for the suitability analysis. The next chapter explains how the suitability analysis can be performed via GIS.

\subsection{GIS and Suitability Analysis}

Due to the geographic data types of these varied criteria and the different analysis approaches, which produce the same output, raster data needed to be combined via the overlaying tool to reach the suitability levels of the alternative nodes. Thus, different analysis approaches accepted to measure the influence of the criteria that produce the proper outputs must be able to be combined with the weighted overlay tool. Fig. 6 illustrates the proposed decision approach for the different types of data.

Hot spot analysis was used to measure a region that is statistically a hot or a cold spot. Nine different clusters emerged for the population, international trade, and handling volumes of seaports. A Euclidean distance analysis was used to find the effects of the locations of the seaports and airports based on the Euclidean distances. For the line type data, a line density analysis was used. This tool analyses the motorway and railway networks. The mentioned analyses were done to measure each decision criterion's spatial effect, and the results are illustrated in Fig. 7.

A geographic model was built to construct the suitability map and maps for several scenarios. Map for each decision criterion was calculated via the mentioned analysis approach and then reclassified to make it ready for the overlay. The weighted overlay tool was used to represent the criteria priorities gathered with the F-AHP approach. Fig. 8 illustrates the suitability map created to evaluate the logistics center locations; Table 5 expresses the suitability levels of each of the logistics center investments.

\subsection{Scenario Analysis and Sensitivity}

Scenarios provide some form of future perspective on an integrated assessment. Since the focused problem is an example of strategic decision, different possible occasions are evaluated to avoid off balance situations. Ad- ditionally, decision environment changes are considered in this step to measure the suitability level changes. To that aim, different scenarios are created and the results are gathered. What-if questions are used during creating the scenarios based on the Delgado and Sendra's (2004) work on sensitivity analysis in spatial decision analysis.

Five scenarios were used to determine various suitability levels under two different considerations. First, the criteria were expected carry different priorities to express future changes, and second, the transportation network was in different structure. Accordingly, first three scenarios focused on the criteria weight changes, and the fourth and fifth criteria considered possible transportation network changes. The scenarios are expressed as follows:

- Scenario 1: In this case, equivalencies of the priorities were considered, and equal priorities were assigned to all seven criteria.

- Scenario 2: In this case, the crucial decision criteria were accepted as transportation, and solely transportation criteria were considered with equal priorities. This scenario was evaluating the convenience for multi-modal transportation.

- Scenario 3: The third scenario devoted to evaluation of the motorway transportation, which plays the major part in the total transportation in Turkey, has higher importance even more than today. For the calculations of the scenario map, the highest weight of 0.60 was assigned to motorway network. Other weights are assigned to $c 1-7$ in sequence as follows: $7 \%, 60 \%, 7 \%, 7 \%, 7 \%, 6 \%$, and $6 \%$.

- Scenario 4: The fourth scenario focuses on establishing a new railway route in the North-West region, where most of the manufacturing industries included in this study are located. This scenario was created to meet the EU's transportation goals (EC 2011).

- Scenario 5: The fifth scenario focused on a new transportation strategy. North-West region of the Turkey faces serious amount of air-traffic. In this scenario, the case of not using air transportation for logistics activities in this area is considered.

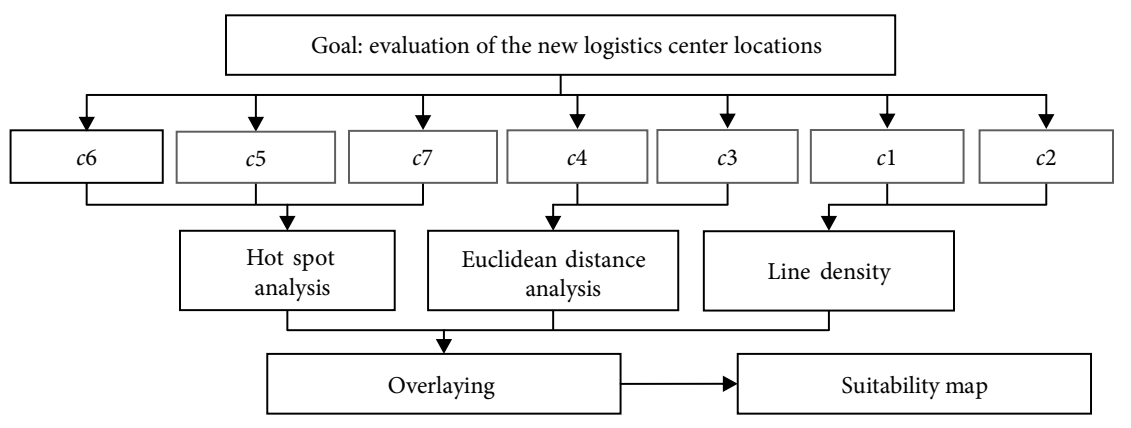

Fig. 6. GIS approaches for different types of data

Table 5. Result preference levels according to the suitability map

\begin{tabular}{|l|c|c|c|c|c|c|c|c|c|c|c|c|c|c|c|c|c|c|c|}
\hline Logistics center & 1 & 2 & 3 & 4 & 5 & 6 & 7 & 8 & 9 & 10 & 11 & 12 & 13 & 14 & 15 & 16 & 17 & 18 & 19 \\
\hline Suitability level & 1 & 2 & 4 & 4 & 5 & 4 & 5 & 4 & 2 & 7 & 4 & 1 & 4 & 3 & 3 & 4 & 5 & 5 & 7 \\
\hline
\end{tabular}




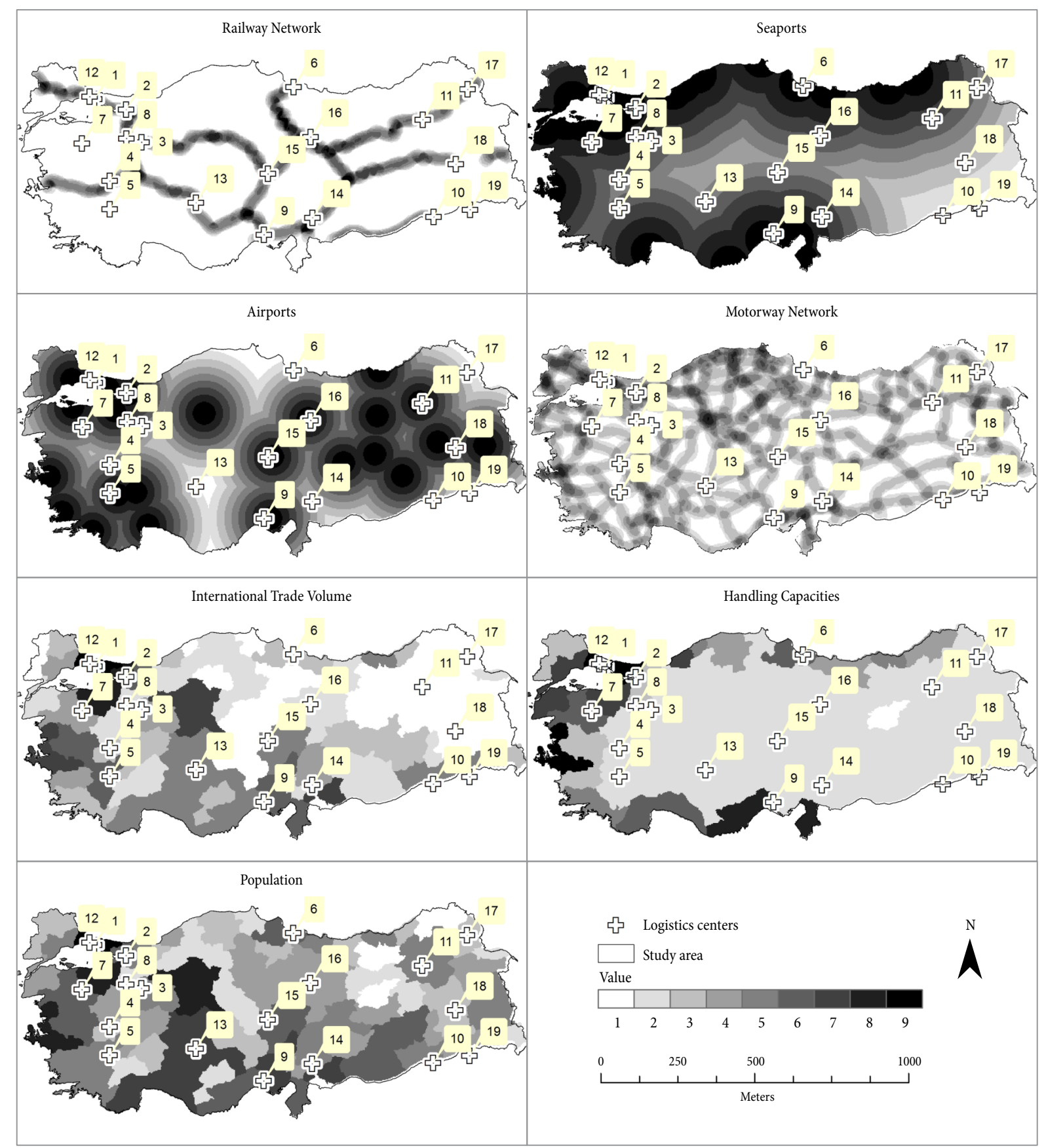

Fig. 7. Reclassified criteria maps

After completing these five scenarios, the suitability values of the alternative set showed differences from the final suitability map that is illustrated in Fig. 8. The new suitability values calculated based on the scenarios are summarized in Table 6. The differentiations between the current suitability levels and the scenarios are illustrated in Fig. 9.

The Scenario 1 gave equal priority levels to each criterion; new weights decreased the suitability levels of the logistics centers. The Scenario 2 focused on proximities to transportation modes and assigned higher importance to the decision criteria. The results of this scenario, which can be seen in the final suitability map, illustrate that most logistics centers in the TCDD project obtain worse suitability levels in relation to their locations.

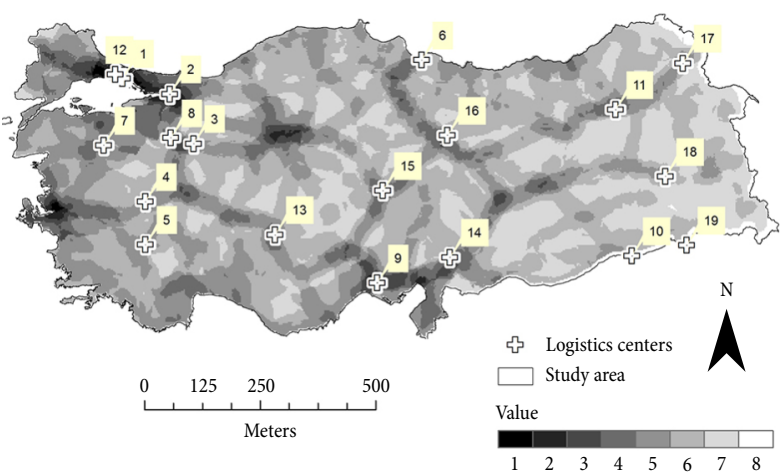

Fig. 8. Suitability map 
Table 6. Preference levels according to the scenario analyses

\begin{tabular}{|l|c|c|c|c|c|c|c|c|c|c|c|c|c|c|c|c|c|c|c|}
\hline Logistics center & 1 & 2 & 3 & 4 & 5 & 6 & 7 & 8 & 9 & 10 & 11 & 12 & 13 & 14 & 15 & 16 & 17 & 18 & 19 \\
\hline Scenario 1 & 1 & 3 & 5 & 6 & 5 & 5 & 5 & 5 & 3 & 7 & 5 & 2 & 5 & 5 & 4 & 5 & 6 & 7 & 7 \\
\hline Scenario 2 & 2 & 3 & 4 & 4 & 5 & 5 & 5 & 3 & 2 & 7 & 3 & 2 & 5 & 5 & 3 & 3 & 5 & 5 & 8 \\
\hline Scenario 3 & 1 & 3 & 5 & 6 & 6 & 6 & 5 & 4 & 3 & 7 & 4 & 2 & 4 & 6 & 4 & 4 & 5 & 6 & 7 \\
\hline Scenario 4 & 1 & 1 & 4 & 4 & 5 & 3 & 5 & 3 & 2 & 6 & 3 & 1 & 3 & 3 & 4 & 3 & 4 & 5 & 6 \\
\hline Scenario 5 & 1 & 3 & 4 & 4 & 5 & 4 & 5 & 4 & 2 & 7 & 4 & 2 & 3 & 3 & 3 & 4 & 5 & 5 & 7 \\
\hline
\end{tabular}
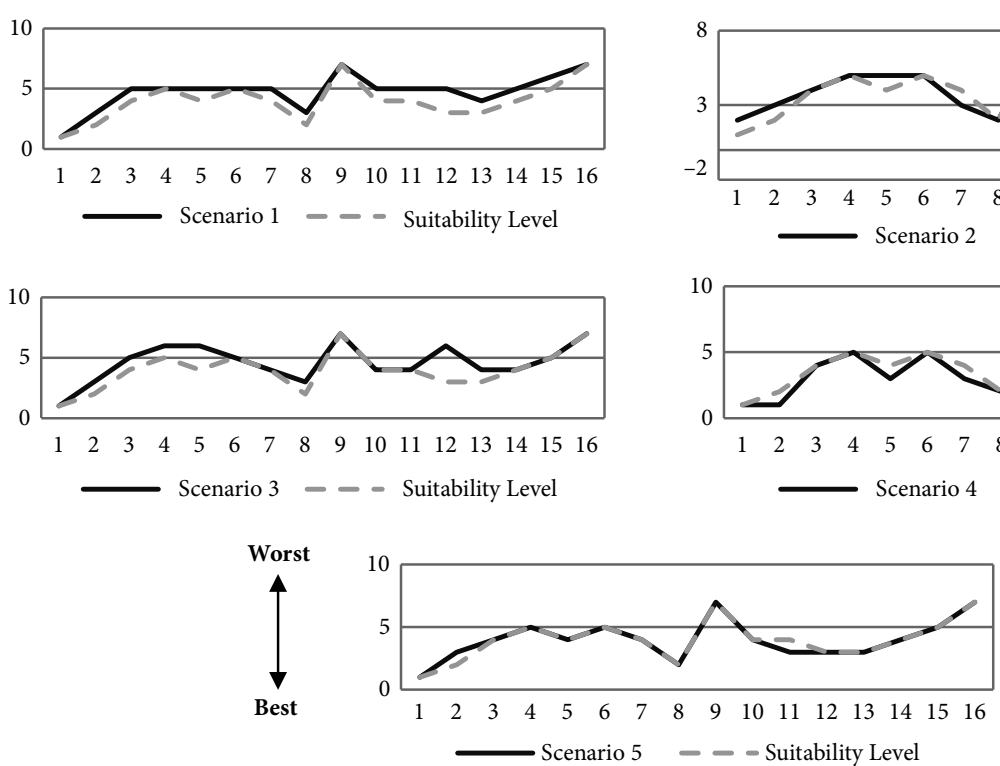

Fig. 9. Preference change representation based on the scenarios

In the Scenario 3, the proximity to the road network was selected as a major factor. According to the Scenario 4, building a new railway arterial positively influences each logistics center's suitability level. Closing down the airports only affects a specific region; this action would not negatively affect other regions.

\section{Conclusions}

The current study investigated the spatial suitability levels of ongoing logistics centers' construction in relation to their locations. To this aim, a multi-step methodology was used to create suitability maps. Expert thoughts on the parameters of the decision, GIS approaches, and the F-AHP technique were integrated to create the evaluation structure. During the first step, decision criteria were determined and the maps of each decision criteria were calculated based on the distances and hot spots. All criteria maps were combined using the calculated criteria priorities, which were found via the F-AHP method. The results of this step yielded the suitability maps that represent the preference levels. The approach integrated the spatial specialties of the decision criteria with the calculated criteria weights based on the F-AHP technique, which is a novel approach for logistics center researches and due to this novelty, it can be said that the paper expands the existing literature and creates innovative outputs for the following studies.
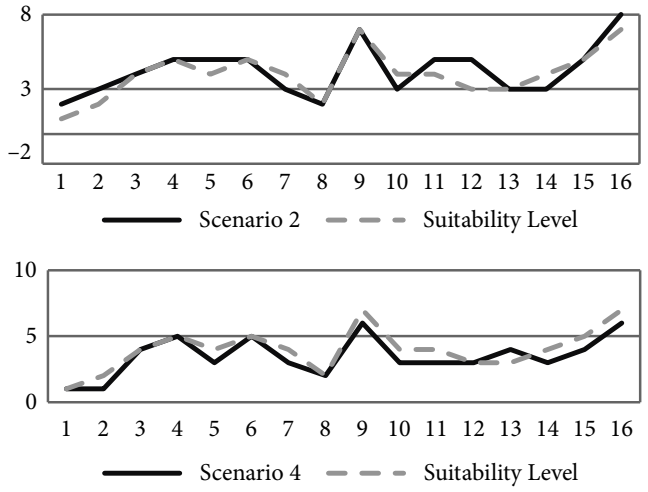

Based on the experts' experiences, seven decision criteria appeared to influence the decision environment; these criteria were supported with the existing literature. Proximities to railroads, highways, seaports, and airports were accepted to represent the distances to the transportation modes. In addition to the transportation criteria, population, international trade volume and the handling capabilities of the seaports were accepted as other factors that influence suitability. After determining the criteria, experts conducted pairwise comparisons to calculate the priority levels and the priority orders. The decision criteria were determined in sequence, as the distance to the highway networks; the distance to the railway network; the volume of the international trade of the cities; and the distance to seaports, airports, seaport handling capabilities, and population.

The overlay tool was used to represent convenience based on criteria priorities. The resulting map was the output of the overlay tool, showing that not all logistics centers were located in the convenient locations. Logistics Centers 1 and 12 were found in the most convenient areas. Centers 2 and 9 were located in the second preference level. Centers 14 and 15 were in the third most convenient area. However, the other thirteen logistics centers were not found in the best three convenient areas.

Different scenarios were created to examine how the decision orders changed in the two approaches. The first approach applied the suitability analysis with dif- 
ferent priorities; the second changed the dataset and created a new decision environment. Subsequently, five scenarios were discussed based on the mentioned approaches. First, the three scenarios focused on priority changes. The results illustrated that the preference levels were changing with the different criteria weights. The 4th and 5th scenarios considered the changes in transportation modes. In scenario 4, establishing a new railroad arterial between the North and South region of Turkey was discussed. The result showed that it provided benefits to the entire country and that suitability levels were increasing due to this new arterial. Scenario 5 considered not allowing air transportation of the NorthWest region; it illustrated that closing down the airports affected the suitability of only four logistics centers.

The current study provided an evaluation of current spatial suitability levels of logistics center locations. Additionally, the method was used to measure possible effects of the scenarios; thus, it can be stated that the method can be used to detect changes in the decision environment. Due to measuring the ability of different cases with different datasets, the methodology can be used for various location selection problems. In this case, the decision selection process should be re-considered and experts who have experience, knowledge, and capability in related area should be selected to evaluate the priority levels of the decision criteria.

Within the study, a land suitability analysis was done for a continuous plane. The results proved that the methodology is working properly for the evaluation of the on-going logistics centers projects. It is possible to increase the number of the candidate areas using this methodology, and the methodology is capable of dealing with various decision alternatives. Though additional comparison could be needed when the preference levels points the same preference levels for an alternative, it might be stated as a limitation for the study. In this case, the mentioned difficulty might be solved using the sensitivity analysis.

The paper proposed a methodology to evaluate the logistics center locations. The findings showed that different criteria influence the study area, and the decision-makers of the logistics system should consider various decision criteria to reach convenient locations. In the following studies, distances travelled by logistics trucks should be evaluated in terms of the total cost and total gas emissions.

\section{References}

Al-Harbi, K. M. A.-S. 2001. Application of the AHP in project management, International Journal of Project Management 19(1): 19-27. http://doi.org/10.1016/S0263-7863(99)00038-1

ArcGIS Resources. 2016. ArcGIS Help 10.1: How Line Density Works. Available from Internet: http://resources.arcgis.com/ en/help/main/10.1/index.html\#//009z00000012000000

Ashrafzadeh, M.; Rafiei, F. M.; Isfahani, N. M.; Zare, Z. 2012. Application of fuzzy TOPSIS method for the selection of warehouse location: a case study, Interdisciplinary Journal of Contemporary Research in Business 3(9): 655-671.
Bozdağ, C. E.; Kahraman, C.; Ruan, D. 2003. Fuzzy group decision making for selection among computer integrated manufacturing systems, Computers in Industry 51(1): 1329. http://doi.org/10.1016/S0166-3615(03)00029-0

Buckley, J. J. 1985. Fuzzy hierarchical analysis, Fuzzy Sets and Systems 17(3): 233-247.

http://doi.org/10.1016/0165-0114(85)90090-9

Chang, D.-Y. 1996. Applications of the extent analysis method on fuzzy AHP, European Journal of Operational Research 95(3): 649-655.

http://doi.org/10.1016/0377-2217(95)00300-2

Christopher, M. 2016. Logistics \& Supply Chain Management. 5th edition. FT Press. 328 p.

Cuomo, A. 2008. Development Profile for Warehouse/Distribution/Logistics Center Sites. 11 p. Available from Internet: http://www.esd.ny.gov/BusinessPrograms/Data/BuildNow/ BNNY_Warehouse-Profile-082608.pdf

Dablanc, L. 2007. Goods transport in large European cities: difficult to organize, difficult to modernize, Transportation Research Part A: Policy and Practice 41(3): 280-285. http://doi.org/10.1016/j.tra.2006.05.005

Delgado, M. G.; Sendra, J. B. 2004. Sensitivity analysis in multicriteria spatial decision-making: a review, Human and Ecological Risk Assessment: An International Journal 10(6): 1173-1187. http://doi.org/10.1080/10807030490887221

Deloitte. 2013. The Logistics Industry in Turkey. Deloitte Türkiye. 114 p. Available from Internet: http://www.invest.gov. tr/en-US/infocenter/publications/Documents/Transportation-Logistics-Industry.pdf

Demirel, T.; Demirel, N. Ç.; Kahraman, C. 2010. Multi-criteria warehouse location selection using Choquet integral, Expert Systems with Applications 37(5): 3943-3952. http://doi.org/10.1016/j.eswa.2009.11.022

Durmuş, A.; Turk, S. S. 2014. Factors influencing location selection of warehouses at the intra-urban level: istanbul case, European Planning Studies 22(2): 268-292. http://doi.org/10.1080/09654313.2012.731038

EC. 2011. White Paper: Roadmap to a Single European Transport Area - Towards a Competitive and Resource Efficient Transport System. COM(2011) 144 final. 28.3.2011, Brussels. Available from Internet: http://eur-lex.europa.eu/legalcontent/EN/ALL/?uri=CELEX:52011DC0144

Erdogan, S.; Yilmaz, I.; Baybura, T.; Gullu, M. 2008. Geographical information systems aided traffic accident analysis system case study: city of Afyonkarahisar, Accident Analysis \& Prevention 40(1): 174-181.

http://doi.org/10.1016/j.aap.2007.05.004

Erkayman, B.; Gundogar, E.; Akkaya, G.; Ipek, M. 2011. A fuzzy TOPSIS approach for logistics center location selection, Journal of Business Case Studies 7(3): 49-55. http://doi.org/10.19030/jbcs.v7i3.4263

Eryürük, S. H.; Kalaoğlu, F; Baskak, M. 2012. A site selection model for establishing a clothing logistics center, Tekstil Ve Konfeksiyon 22(1): 40-47.

Getis, A.; Ord, J. K. 1992. The analysis of spatial association by use of distance statistics, Geographical Analysis 24(3): 189206. http://doi.org/10.1111/j.1538-4632.1992.tb00261.x

Guasch, J. L.; Kogan, J. 2001. Inventories in Developing Countries: Levels and Determinants - a Red Flag for Competitiveness and Growth. Policy Research Working Paper No 2552. The World Bank, Washington, DC. 30 p. Available from Internet: http://www-wds.worldbank.org/servlet/WDSContentServer/WDSP/IB/2001/03/26/000094946_010313 05310524/Rendered/PDF/multi0page.pdf 
Gumus, I.; Onden, I. 2014. Using spatial information for international market alternatives ordering, in UNF International Business Conference on Teaching Research and Practice - 14, 21-22 February 2014, University of North Florida, Jacksonville, FL, 1-5.

Jankowski, P.; Richard, L. 1994. Integration of GIS-based suitability analysis and multicriteria evaluation in a spatial decision support system for route selection, Environment and Planning B: Planning and Design 21(3): 323-340. http://doi.org/10.1068/b210323

Jenks, G. F. 1967. The data model concept in statistical mapping, International Yearbook of Cartography 7: 186-190.

Kahraman, C.; Beskese, A.; Ruan, D. 2004. Measuring flexibility of computer integrated manufacturing systems using fuzzy cash flow analysis, Information Sciences 168(1-4): 77-94. http://doi.org/10.1016/j.ins.2003.11.004

Kahraman, C.; Kaya, İ.; Cebi, S. 2009. A comparative analysis for multiattribute selection among renewable energy alternatives using fuzzy axiomatic design and fuzzy analytic hierarchy process, Energy 34(10): 1603-1616. http://doi.org/10.1016/j.energy.2009.07.008

Kahraman, C.; Süder, A.; Kaya, İ. 2014. Fuzzy multicriteria evaluation of health research investments, Technological and Economic Development of Economy 20(2): 210-226. http://doi.org/10.3846/20294913.2013.876560

Kayikci, Y. 2010. A conceptual model for intermodal freight logistics centre location decisions, Procedia - Social and Behavioral Sciences 2(3): 6297-6311. http://doi.org/10.1016/j.sbspro.2010.04.039

Kuo, R. J.; Chi, S. C.; Kao, S. S. 2002. A decision support system for selecting convenience store location through integration of fuzzy AHP and artificial neural network, Computers in Industry 47(2): 199-214. http://doi.org/10.1016/S0166-3615(01)00147-6

Levine, N. 2006. Crime mapping and the CrimeStat program, Geographical Analysis 38(1): 41-56. http://doi.org/10.1111/j.0016-7363.2005.00673.x

Liou, T.-S.; Wang, M.-J. J. 1992. Ranking fuzzy numbers with integral value, Fuzzy Sets and Systems 50(3): 247-255. http://doi.org/10.1016/0165-0114(92)90223-Q

Liu, N.; Huang, B.; Chandramouli, M. 2006. Optimal siting of fire stations using GIS and ANT algorithm, Journal of Computing in Civil Engineering 20(5): 361-369. http://doi.org/10.1061/(ASCE)0887-3801(2006)20:5(361)

Maister, D. H. 1976. Centralisation of inventories and the "square root law", International Journal of Physical Distribution 6(3): 124-134. http://doi.org/10.1108/eb014366

McCoy, J.; Johnston, K.; Kopp, S.; Borup, B.; Willison, J. 2004. ArcGIS 9: Using ArcGIS Spatial Analyst. 4th edition. ESRI Press. 233 p.

McKinnon, A. 2009. The present and future land requirements of logistical activities, Land Use Policy 26(1): S293-S301. http://doi.org/10.1016/j.landusepol.2009.08.014

Mon, D.-L.; Cheng, C.-H.; Lin, J.-C. 1994. Evaluating weapon system using fuzzy analytic hierarchy process based on entropy weight, Fuzzy Sets and Systems 62(2): 127-134. http://doi.org/10.1016/0165-0114(94)90052-3

Nathanail, E. 2007. Developing an integrated logistics terminal network in the CADSES, Transition Studies Review 14(1): 125-146. http://doi.org/10.1007/s11300-007-0139-y

Ocalir, E. V.; Ercoskun, O. Y.; Tur, R. 2010. An integrated model of GIS and fuzzy logic (FMOTS) for location decisions of taxicab stands, Expert Systems with Applications 37(7): 4892-4901. http://doi.org/10.1016/j.eswa.2009.12.026
Onden, I.; Tuzla, H.; Cobb, S. 2012. Evaluation of retail store location alternatives for investment decisions using the Delphi technique and geographic information systems, International Business: Research, Teaching and Practice 6(2): 64-75.

Özcan, T.; Çelebi, N.; Esnaf, Ş. 2011. Comparative analysis of multi-criteria decision making methodologies and implementation of a warehouse location selection problem, Expert Systems with Applications 38(8): 9773-9779. http://doi.org/10.1016/j.eswa.2011.02.022

Özdemir, D. 2010. Strategic choice for Istanbul: a domestic or international orientation for logistics?, Cities 27(3): 154163. http://doi.org/10.1016/j.cities.2009.12.003

Purba, J. H.; Lu, J.; Ruan, D.; Zhang, G. 2010. A Hybrid approach for fault tree analysis combining probabilistic method with fuzzy numbers, Lecture Notes in Computer Science 6113: 194-201.

http://doi.org/10.1007/978-3-642-13208-7_25

Rantasila, K.; Ojala, L. 2012. Measurement of national-level logistics costs and performance, International Transport Forum Discussion Papers 4: 1-62 http://doi.org/10.1787/5k8zvv79pzkk-en

RTMTMC. 2014. Deniz Ticareti 2013 İstatistikleri: Deniz Taşıtları, Denizyolu Taşıma Ve Teşvik İstatistikleri. Republic of Türkiye Ministry of Transport, Maritime and Communications (RTMTMC). 99 s. Available from Internet: http://www.ubak.gov.tr/BLSM_WIYS/DTGM/tr/Kitaplar/20140613_162122_64032_1_64480.pdf (in Turkish).

Rodrigue, J.-P.; Comtois, C.; Slack, B. 2013. The Geography of Transport Systems. 3rd edition. Routledge. 432 p.

Rodrigues, A. M.; Bowersox, D. J.; Calantone, R. J. 2005. Estimation of global and national logistics expenditures: 2002 data update, Journal of Business Logistics 26(2): 1-16. http://doi.org/10.1002/j.2158-1592.2005.tb00202.x

Saaty, T. L. 1990. How to make a decision: the analytic hierarchy process, European Journal of Operational Research 48(1): 9-26. http://doi.org/10.1016/0377-2217(90)90057-I

Saaty, T. L. 2008. Decision making with the analytic hierarchy process, International Journal of Services Sciences 1(1): 83-98. http://doi.org/10.1504/IJSSCI.2008.017590

Sengpiehl, C.; Wu, Y.; Nagel, P. 2009. Logistics cities: a spatial requirement framework, in Proceedings of the 14th International Symposium on Logistics (14th ISL), 5-8 July 2009, Istanbul, Turkey, 586-594.

Truong, L.T.; Somenahalli, S. V. C. 2011. Using GIS to identify pedestrian-vehicle crash hot spots and unsafe bus stops, Journal of Public Transportation 14(1): 99-114. http://doi.org/10.5038/2375-0901.14.1.6

Tsamboulas, D. A.; Kapros, S. 2003. Freight village evaluation under uncertainty with public and private financing, Transport Policy 10(2): 141-156. http://doi.org/10.1016/S0967-070X(03)00002-7

TUIK. 2014a. Address Based Population Registration System. Turkish Statistical Institute (TUIK). Available from Internet: http://www.turkstat.gov.tr

TUIK. 2014b. Foreign Trade Statistics: Foreign Trade by Years. Turkish Statistical Institute (TUIK). Available from Internet: http://www.turkstat.gov.tr

Uçal Sarı, I.; Öztayşi, B.; Kahraman, C. 2013. Fuzzy analytic hierarchy process using type-2 fuzzy sets: an application to warehouse location selection, in M. Doumpos, E. Grigoroudis (Eds.). Multicriteria Decision Aid and Artificial Intelligence: Links, Theory and Applications, 285-308. http://doi.org/10.1002/9781118522516.ch12 
UTIKAD. 2012. Türk Lojistik Sektörü Değerlendirmesi. Association of International Forwarding and Logistics Service Providers (UTIKAD). 61 p. Available from Internet: http://www.utikad.org.tr/db/files/TurkLojistikSektoruDegerlendirmesi.pdf (in Turkish).

Vahidnia, M. H.; Alesheikh, A. A.; Alimohammadi, A. 2009. Hospital site selection using fuzzy AHP and its derivatives, Journal of Environmental Management 90(10): 3048-3056. http://doi.org/10.1016/j.jenvman.2009.04.010

Van Laarhoven, P. J. M.; Pedrycz, W. 1983. A fuzzy extension of Saaty's priority theory, Fuzzy Sets and Systems 11(1-3): 229-241. http://doi.org/10.1016/S0165-0114(83)80082-7

Vlachopoulou, M.; Silleos, G.; Manthou, V. 2001. Geographic information systems in warehouse site selection decisions, International Journal of Production Economics 71(1-3): 205-212. http://doi.org/10.1016/S0925-5273(00)00119-5

Wang, Y.-M.; Luo, Y.; Hua, Z. 2008. On the extent analysis method for fuzzy AHP and its applications, European Journal of Operational Research 186(2): 735-747.

http://doi.org/10.1016/j.ejor.2007.01.050

Wittmann, H. 2010. Total costs of logistics in South Africa need to be reduced, CSIR ScienceScope 5(1): 4-39. Available from Internet: http://www.csir.co.za/publications/ pdfs/2.2_SS_BE_transport\&logistics_chap1.pdf

Zhou, L.; Wu, J. 2012. GIS-Based Multi-Criteria Analysis for Hospital Site Selection in Haidian District of Beijing. Student Thesis, Master Programme in Geomatics. University of Gävle, Sweden. 50 p.

Zucca, A.; Sharifi, A. M.; Fabbri, A. G. 2008. Application of spatial multi-criteria analysis to site selection for a local park: A case study in the Bergamo Province, Italy, Journal of Environmental Management 88(4): 752-769.

http://doi.org/10.1016/j.jenvman.2007.04.026 